\title{
Band spectrum transformation and temperature dependences of thermoelectric power of $\mathrm{Hg}_{1-x} \mathrm{R}_{x} \mathrm{Ba}_{2} \mathrm{Ca}_{2} \mathrm{Cu}_{3} \mathrm{O}_{8+\delta}$ system
}

\author{
O. Babych|; I. Gabriel, R. Lutsiv, M. Matviyiv, M. Vasyuk \\ Ivan Franko National University of Lviv, 50 Dragomanov Str., 79005 Lviv, Ukraine
}

Received September 28, 2009, in final form May 31, 2010

Temperature dependences of thermoelectric power $\mathrm{S}(\mathrm{T})$ at $T>T_{\mathrm{c}}$ of the $\mathrm{Hg}$-based high temperature superconductors $\mathrm{Hg}_{1-x} \mathrm{R}_{x} \mathrm{Ba}_{2} \mathrm{Ca}_{2} \mathrm{Cu}_{3} \mathrm{O}_{8+\delta}(\mathrm{R}=\mathrm{Re}, \mathrm{Pb})$ have been analyzed with accounting for strong scattering of charge carriers. Transformation of parameters of a narrow conducting band in the region of the Fermi level was studied. The existence of correlation between the effective bandwidth and the temperature of a superconductive transition $T_{\mathrm{c}}$ is shown.

Key words: high-temperature superconductivity, superconductive transition temperature, thermoelectric power, narrow conduction band, peak of density of states, Fermi level

PACS: 74.25.Fy, 74.62.Dh, 74.72.Jt

\section{Introduction}

When studying high temperature superconductors (HTSC), it is important to identify correlation between major peculiarities of the transport process of charge carriers in normal phase $T>T_{\mathrm{c}}$ and the calculated or model densities of states in the vicinity of the Fermi level.

According to the band calculations, the Fermi level for $\mathrm{YBaCuO}, \mathrm{HgBaCuO}$ and other cuprates is near (on a slope) the narrow peak of the density of states (DOS) formed by overlapping of the $p-$ and $d$-bands [1, 2]. Therefore, the usage of the narrow band phenomenological model to explain peculiarities in the behavior of the HTSC materials (see for example 3]) is understandable. There are considerable discrepancies concerning the role of various atoms and their positions in the elementary cell in the formation of the conductive band. The data of band-structure calculations show that the peak in the density of states exists against the background of a considerably wider band. However, if the Fermi level is located within this narrow energy interval, where the value of the density of states is larger than beyond this interval, then this peak plays a dominat role in the properties of the normal state and possibly of the superconductive state as well. The width of this band is of the order of $k_{\mathrm{B}} T$. Therefore, all its levels can make a considerable contribution to the transport of electrons.

It should be noted that absolute values, slopes of curves of temperature dependences of the Hall coefficient $R_{x}$ and resistivity $\rho$ in particular, vary depending on structure defects, microcracks, and granularity of the medium. Contribution of the component that is related to imperfections, to thermoelectric power is considerably smaller. Experimental data on $S(T)$ obtained by different authors for samples with equal compositions are close to each other and good reproducibility of the results is observed. Therefore, differences in values and dependences with the change of composition should be explained by specific features of electronic structure. Moreover, using theoretical expressions, one can calculate the absolute values of thermoelectric power, whereas resistivity and the Hall coefficient can be calculated with an accuracy to a constant because of the lack of necessary data on the material parameters. Due to the aforementioned features, the analysis in the present study was based on the temperature dependences of thermoelectric power.

*E-mail: orestbabych@gmail.com 


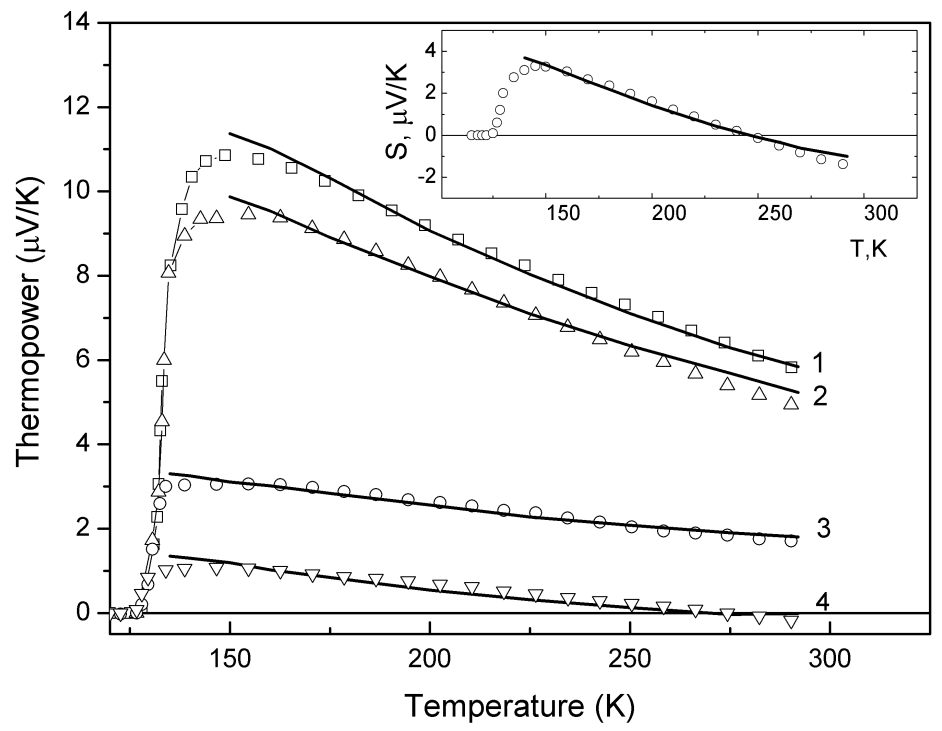

Figure 1. Temperature dependences of thermopower $\mathrm{HgBa}_{2} \mathrm{Ca}_{2} \mathrm{Cu}_{3} \mathrm{O}_{8+\delta}$ annealed under various conditions [12], solid lines - calculation results:

1. $E_{0}=-6.40 \mathrm{meV}, W=45.9 \mathrm{meV}, W_{1} / W_{2}=0.70, D\left(E_{\mathrm{F}}\right)=21.58 \mathrm{eV}^{-1}, F=0.474, T_{\mathrm{c}}=128.7 \mathrm{~K}$;

2. $E_{0}=-4.60 \mathrm{meV}, W=45.0 \mathrm{meV}, W_{1} / W_{2}=0.80, D\left(E_{\mathrm{F}}\right)=21.96 \mathrm{eV}^{-1}, F=0.488, T_{\mathrm{c}}=130.0 \mathrm{~K}$;

3. $E_{0}=-1.18 \mathrm{meV}, W=43.0 \mathrm{meV}, W_{1} / W_{2}=0.96, D\left(E_{\mathrm{F}}\right)=23.23 \mathrm{eV}^{-1}, F=0.499, T_{\mathrm{c}}=133.0 \mathrm{~K}$;

4. $E_{0}=-1.61 \mathrm{meV}, W=44.1 \mathrm{meV}, W_{1} / W_{2}=0.87, D\left(E_{\mathrm{F}}\right)=22.72 \mathrm{eV}^{-1}, F=0.484, T_{\mathrm{c}}=131.6 \mathrm{~K}$;

In insert: experimental (o) and calculation (-) data of thermopower $\mathrm{Hg}_{0.8} \mathrm{~Pb}_{0.2} \mathrm{Ba}_{2} \mathrm{Ca}_{2} \mathrm{Cu}_{3} \mathrm{O}_{8+\delta}$ : $E_{0}=-4.7 \mathrm{meV}, W=47.5 \mathrm{meV}, W_{1} / W_{2}=0.67, D\left(E_{\mathrm{F}}\right)=21.50 \mathrm{eV}^{-1}, F=0.453, T_{\mathrm{c}}=126.5 \mathrm{~K}$.

The use of the band densities of states does not always make it possible to explain the transport properties of the HTSC. This can be attributed to the fact that correlation effects are not taken into account in the one electron approximation of the band theory. Furthermore, there is frequently no information on electronic structure of compounds with deviations of their compositions from stoichiometry. That is why we have used a model presentation of the density of states in the Lorentz form:

$$
D(E)=\frac{1}{\pi} \frac{W}{\left(E-E_{0}\right)^{2}+W^{2}}
$$

where $E_{0}$ - is the distance of the peak of DOS from the Fermi level, $W$ - is the width of DOS peak. Thermoelectric power temperature depedence in the phenomenological model term of narrow band using reference [4] has been calculated:

$$
S(T)=-\frac{1}{|\mathrm{e}| T} \frac{I_{1}}{I_{0}}
$$

where

$$
\begin{gathered}
I_{1}=\int \sigma_{E}\left(-\frac{d f}{d E}\right)\left(E-E_{\mathrm{F}}\right) \mathrm{d} E, \\
I_{0}=\int \sigma_{E}\left(-\frac{d f}{d E}\right) \mathrm{d} E,
\end{gathered}
$$

where $\sigma_{E}$ - is the conductivity at $T \rightarrow 0$, sensitive to the fine structure of the density of states near $E_{\mathrm{F}}, f\left(E-E_{\mathrm{F}}\right)$ - the Fermi distribution function. Resistivity is inversely proportional to:

$$
\rho(T) \sim 1 / I_{0}=1 / \int \sigma_{E}\left(-\frac{d f}{d E}\right) \mathrm{d} E .
$$


To analyse the results obtained we estimated the degree of band filling by electrons:

$$
F(T)=\frac{\int f\left(E-E_{\mathrm{F}}\right) D(E) \mathrm{d} E}{\int D(E) \mathrm{d} E} .
$$

When selecting the type of scattering of carriers, one ought to note that during the interpretation of analogous dependences of $S(T)$ in intermetallic systems with intermediate valence and heavy fermions on the base of the $4 f-, 3 d$-transition elements, logical results can be obtained by assuming $\sigma_{E} \sim D^{-1}(E)$ (the Mott model - rather weak scattering, attributed mainly to the $p-d$ transitions) [5, [6]. Values of the mobility of carriers and conductivity for samples of HTSC are comparatively small [7, 8], and thus we have used the dependence on the basis of the Kubo-Greenwood formula $\sigma_{E} \sim D^{2}(E)$ (general case of a strong scattering).

\section{Technical data-out}

Members of the mercury homological series $\mathrm{HgBa}_{2} \mathrm{Ca}_{n-1} \mathrm{Cu}_{n} \mathrm{O}_{2 n+n+\delta}$, which demonstrate the highest currently known temperature of transition in a superconductive state $T_{\mathrm{c}}(n=3)$, of the order of $130 \mathrm{~K}$ and $160 \mathrm{~K}$ both at atmospheric [9] and increased pressures [10, 11], correspondingly, were selected as objects for the study. There is a large amount of published experimental data for these superconductive ceramics on temperature dependences of thermoelectric power during cationic substitutions and anionic doping.

The experimental data for $\mathrm{HgBa}_{2} \mathrm{Ca}_{2} \mathrm{Cu}_{3} \mathrm{O}_{8+\delta}$ (figure 1) and $\mathrm{Hg}_{0.82} \mathrm{Re}_{0.18} \mathrm{Ba}_{2} \mathrm{Ca}_{2} \mathrm{Cu}_{3} \mathrm{O}_{8+\delta}$ (figure 2) are available from [12, 13]. Temperature dependences of thermoelectric power features with

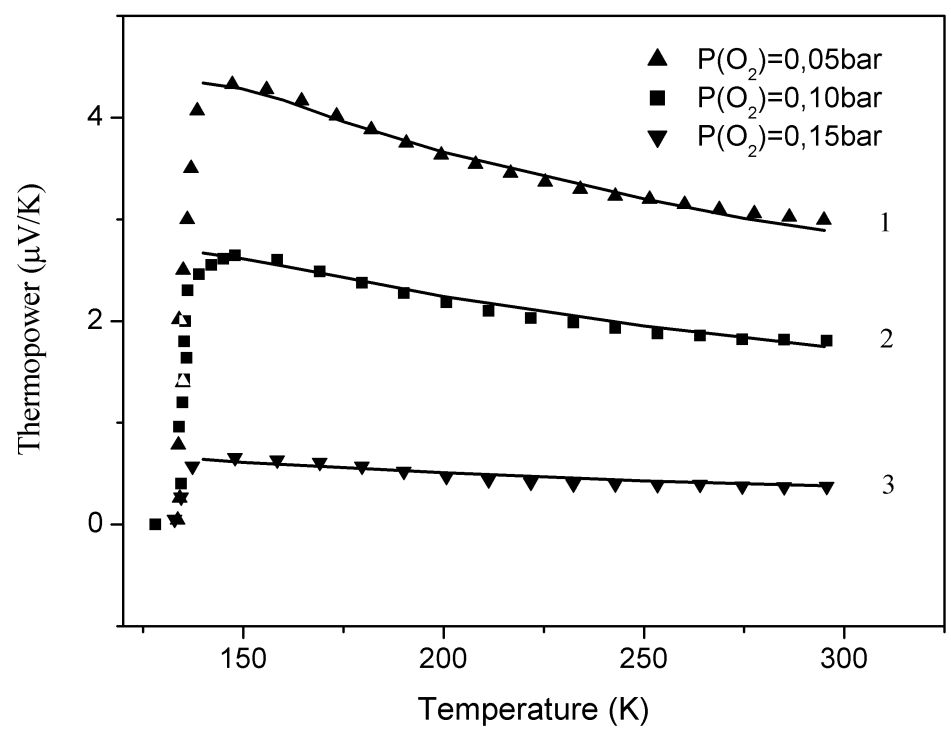

Figure 2. Temperature dependences of thermopower $\mathrm{Hg}_{0.82} \mathrm{Re}_{0.18} \mathrm{Ba}_{2} \mathrm{Ca}_{2} \mathrm{Cu}_{3} \mathrm{O}_{8+\delta}$ annealed under various conditions [13], solid lines - calculation results:

1. $E_{0}=-1.08 \mathrm{meV}, W=43.3 \mathrm{meV}, W_{1} / W_{2}=0.99, D\left(E_{\mathrm{F}}\right)=23.06 \mathrm{eV}^{-1}, F=0.506, T_{\mathrm{c}}=132.6 \mathrm{~K}$;

2. $E_{0}=-0.63 \mathrm{meV}, W=42.8 \mathrm{meV}, W_{1} / W_{2}=1.00, D\left(E_{\mathrm{F}}\right)=23.36 \mathrm{eV}^{-1}, F=0.504, T_{\mathrm{c}}=133.2 \mathrm{~K}$;

3. $E_{0}=-0.20 \mathrm{meV}, W=43.2 \mathrm{meV}, W_{1} / W_{2}=0.99, D\left(E_{\mathrm{F}}\right)=23.16 \mathrm{eV}^{-1}, F=0.500, T_{\mathrm{c}}=132.7 \mathrm{~K}$.

clearly visible maximum at temperatures above the superconductive transition, are presented as a section of practically linear fall-off with temperature increasing up to $290 \mathrm{~K}$. Authors of this paper synthesized the samples and measured $\rho(T), T_{\mathrm{c}}$ and $S(T)$ when $\mathrm{Hg}$ is substituted for $\mathrm{Pb}$ (see figure 1, insert). Introduction of $\mathrm{Re}, \mathrm{Pb}$ and some other elements results in an improvement of chemical stability without considerable losses of initial value for $T_{\mathrm{c}}$. Values of the thermoelectric 
power decrease up to possible sign inversion for certain compositions with an increase of oxygen content both in pure and doped samples.

\section{Results and discussion}

Analyzing the temperature dependences of thermoelectric power in the model of a narrow band and reaching a qualitative matching between the calculated and experimental data, it is possible to estimate the band spectrum parameters and trace their transformation with variations of composition of the samples.

Representation of the peak of the density of states in the form of a symmetric Lorentzian (11) does not yield satisfactory results. Good agreement of the calculation with experimental dependences at $T>T_{\mathrm{c}}$, in particular inversion of the thermoelectric conductivity sign, can be obtained using a asymmetric peak of the density of states, which is defined by a position of the $E_{0}$ maximum relatively to the Fermi level and the two half band widths $W_{1}$ at $E<E_{0}$ and $W_{2}$ at $E>E_{0}$. The average value of $W=\left(W_{1}+W_{2}\right) / 2$ is presented in the paper. Let us note the following point: if the band filling degree $F>1 / 2$, then symmetric Lorentz distribution is below $E_{\mathrm{F}}$ and $S>0$; if $F<1 / 2$, it is higher than $E_{\mathrm{F}}$ and $S<0$, and if $F=1 / 2-S=0$. In the case of an asymmetric band, positive values of $S$ can be also observed at $F \leqslant 1 / 2$.

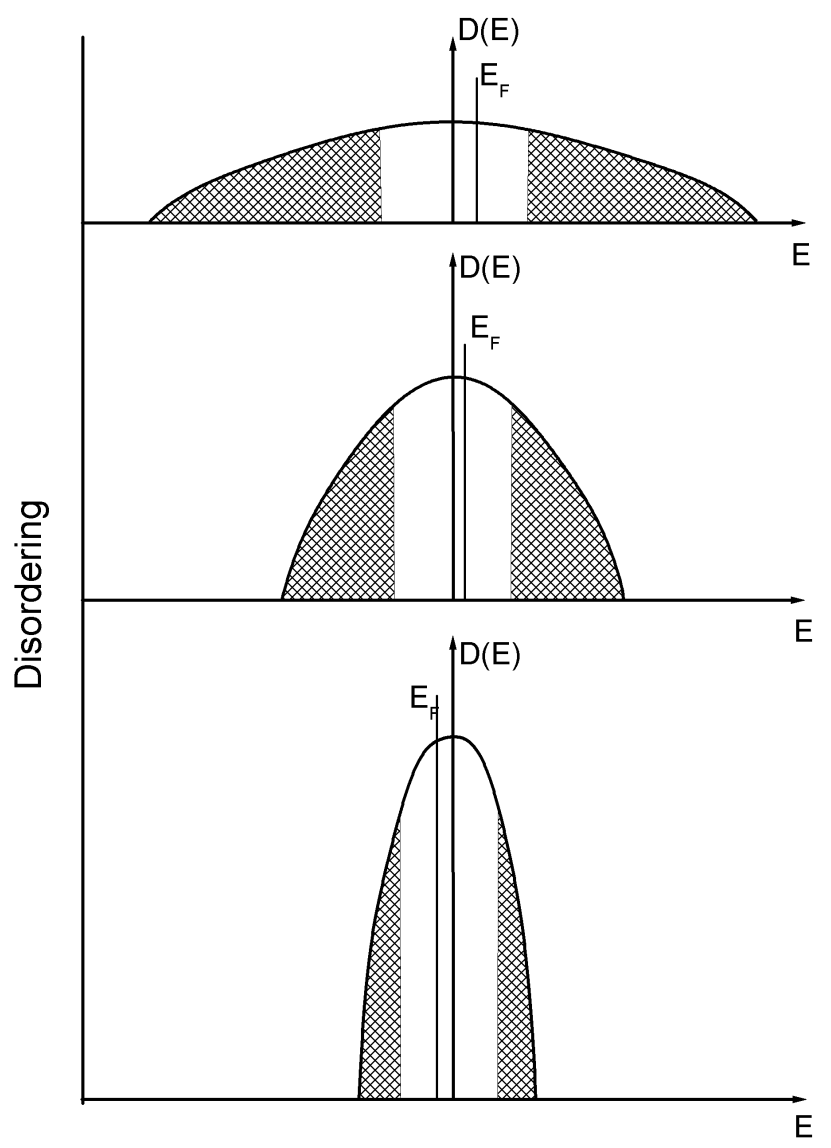

Figure 3. Band broadening, increase of the part of localized states at the band edges (shaded areas), fall of the density of states at the Fermi level $D\left(E_{\mathrm{F}}\right)$ as a function of structure disordering.

The results of the calculations using the approach described above for $\mathrm{HgBa}_{2} \mathrm{Ca}_{2} \mathrm{Cu}_{3} \mathrm{O}_{8+\delta}$ in the region of optimal oxygen doping are shown in figure 11. Here, the degree of band filling 
decreases in the whole range when the oxygen index $\delta$ grows, which corresponds to the acceptor type of additional ions of oxygen introduced in the system. When the bandwidth increases in the vicinity of the optimal doping region (curves 2 and 4 in figure11), the density of states at the Fermi level $D\left(E_{\mathrm{F}}\right)$ decreases, which correlates with a decrease of $T_{\mathrm{c}}$. This can be related to the lattice disordering (increase of structural defects) when oxygen content deviates from the optimal one (curve 3) both downwards (curve 2) and upwards (curve 4). This is confirmed by an increase of the band asymmetry $\left(W_{1} / W_{2}\right)$ for compositions 2,4 as compared with composition 3 . Consequently, the largest $T_{\mathrm{c}}$ (maximal ordering degree) corresponds to sample 3 .

An analogous type of the band spectrum transformation was obtained during the analysis of temperature dependences of thermoelectric power of the $\mathrm{Hg}_{0.82} \mathrm{Re}_{0.18} \mathrm{Ba}_{2} \mathrm{Ca}_{2} \mathrm{Cu}_{3} \mathrm{O}_{8+\delta}$ system with variation of the oxygen index $\delta$ (figure2). Here, correlation between the conducting band width and correspondingly density of states on the $E_{\mathrm{F}}$ and the temperature of transition in superconductive state is also observed, i.e., larger values of $T_{\mathrm{c}}$ for composition 2 as compared to the 1 and 3 .

The relationships obtained correspond to the Anderson model: band broadening, increase of the part of localized states at the band edges, the drop of the density of states at the Fermi level $D\left(E_{\mathrm{F}}\right)$ as a function of disordering structure (figure 3 ), which corresponds to a type of transformation of the band spectrum and temperatures of superconductive transition obtained from calculation.

Comparing the dependences $S(T)$ for pure $\mathrm{Hg}-1223$ samples and those optimally doped with oxygen (figure 1) with the experimental obtained data for $\mathrm{Hg}_{0.8} \mathrm{Re}_{0.2} \mathrm{Ba}_{2} \mathrm{Ca}_{2} \mathrm{Cu}_{3} \mathrm{O}_{8+\delta}$ (insert in the figure 1), it is found that the inversion is only observed for the $(\mathrm{Hg}, \mathrm{Pb})-1223$ samples for one level $\alpha_{\max } \cong 3 \mu \mathrm{V} / \mathrm{K}$ with the increase of temperature, which points to additional introduction of holes due to cationic substitution. This is confirmed by the calculation results: with such substitution of mercury by lead, there takes place a decrease of the degree of band filling by electrons, a growth of its symmetry and width, and correspondingly a decay of the $D\left(E_{\mathrm{F}}\right)$, which corresponds to the change of $T_{\mathrm{c}}$ (figure 1).

The results of calculations enabled us to assess an impact of various cationic and anionic substitutions in $\mathrm{Hg}$-containing HTSC not only on the band spectrum parameters, but also on critical temperature, as well as to trace the relationship between them. Figure 4 graphically depicts the correlation between $T_{\mathrm{c}}$ and the bandwidth $W$. Reduction of the density of states value at the Fermi level due to the band broadening can be caused by a decrease of the $T_{\mathrm{c}}$.

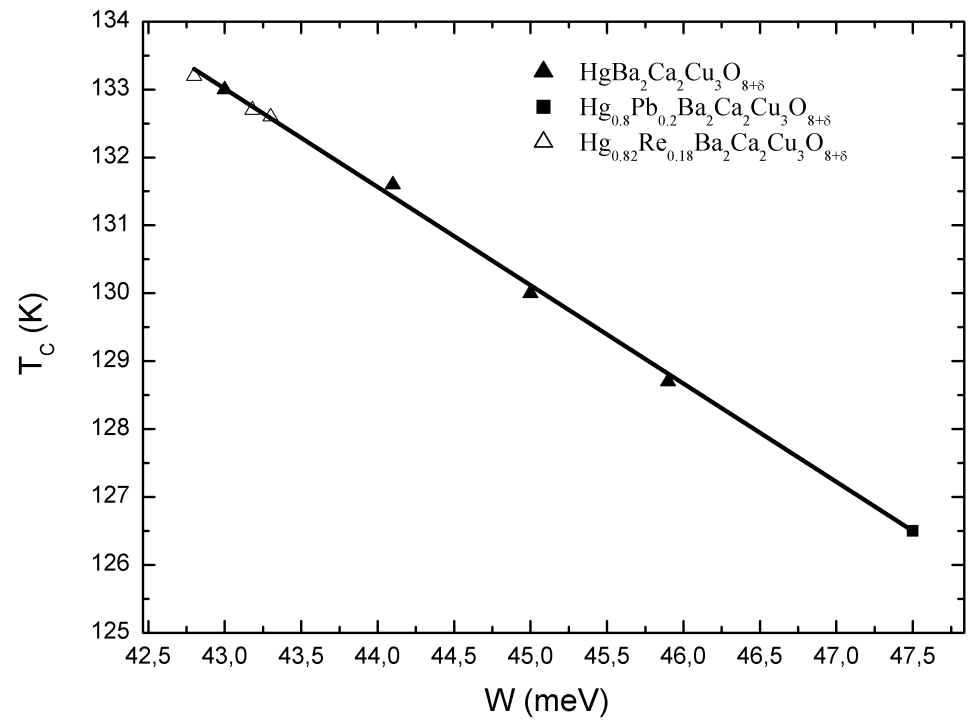

Figure 4. Correlative dependence between critical temperature and effective conducting bandwidth $T_{\mathrm{c}}(W)$ in the system of $\mathrm{Hg}_{1-x} \mathrm{R}_{x} \mathrm{Ba}_{2} \mathrm{Ca}_{2} \mathrm{Cu}_{3} \mathrm{O}_{8+\delta}(\mathrm{R}=\mathrm{Re}, \mathrm{Pb})$. 


\title{
4. Conclusion
}

Using a representation of the peak of the density of states in the region of the Fermi level in the form of an asymmetric Lorentz distribution, good agreement of the calculated temperature dependences of the thermoelectric power with experimental data at $T>T_{\mathrm{c}}$ has been obtained. The type of the behaviour of thermoelectric power of the $\mathrm{Hg}$ - containing high temperature superconductors being studied, with cationic substitution and anionic doping, is defined by such parameters of the narrow conduction band in the region of the Fermi level as its width $W$, population by electrons $F$ and values of the density of states $D\left(E_{\mathrm{F}}\right)$. Existence of correlation between the effective band width and the temperature of superconductive transition has been shown during establishing interrelation between properties of the normal state and superconductive characteristics.

\section{References}

1. Mattheiss L.F., Hamann D.R., Solid State Commun., 1987, 63, 395; doi:10.1016/0038-1098(87)91136-7.

2. Novikov D.L., Freeman A.J., Physica C, 1993, 212, 233; doi:10.1016/0921-4534(93)90509-O

3. Moshchalkov V.V., Physica C, 1988, 156, 473; doi:10.1016/0921-4534(88)90190-6

4. Mott N.F., Davis E.A., Electronic processes in non-crystalline materials. Oxford Univ. Press, Oxford, 1979.

5. Koterlyn M.D., Babych O.I., Koterlyn G.M., J. Alloys Compd., 2001, 325, 6; doi:10.1016/S0925-8388(01)01007-6

6. Koterlin M.D., Babich O.I., Yasnitskii R.I., Physics of the Solid State, 2002, 44, 823; doi: $10.1134 / 1.1477479$

7. Chen J.T., McEwan C.J., Wenger L.E., Logothetis E.M., Phys. Rev. B, 1987, 35, 7124; doi:10.1103/PhysRevB.35.7124.

8. Subramaniam C.K., Paranthaman M., Kaiser A.B., Phys. Rev. B, 1995, 51, 1330; doi:10.1103/PhysRevB.51.1330.

9. Schilling A., Cantoni M., Guo J.D., Ott H.R., Nature, 1993, 363, 56; doi:10.1038/363056a0.

10. Chu C.W. et al., Nature, 1993, 365, 323; doi:10.1038/365323a0

11. Gao L., Xue Y.Y., Chen F., Xiong Q., Phys. Rev. B, 1994, 50, 4260; doi:10.1103/PhysRevB.50.4260.

12. Chen F. et al., Preprint $\mathrm{T}_{\mathrm{C}} \mathrm{SUN}, 96: 006,1996$.

13. Passos C.A.C., Orlando M.T.D., Passamai J.L., de Mello E.V. Preprint arXiv:cond-mat/0506387, 2005.

\section{Трансформація зонного спектру та температурні залежності коефіцієнта термоелектрорушійної сили в системі $\mathrm{Hg}_{1-x} \mathrm{R}_{x} \mathrm{Ba}_{2} \mathrm{Ca}_{2} \mathrm{Cu}_{3} \mathrm{O}_{8+\delta}$}

\author{
О. Бабич, І. Габрієль, Р. Луців, М. Матвіїв, М. Васюк \\ Львівський національний університет імені Івана Франка, вул. Драгоманова, 50, Львів, Україна
}

3 врахуванням сильного розсіювання носіїв заряду проведено аналіз температурних залежностей коефіцієнта термоелектрорушійної сили $\mathrm{S}(\mathrm{T})$ при $\mathrm{T}>\mathrm{T}_{\mathrm{c}}$ ртутьвмісних високотемпературних надпровідників (ВТНП) $\mathrm{Hg}_{1-x} \mathrm{R}_{x} \mathrm{Ba}_{2} \mathrm{Ca}_{2} \mathrm{Cu}_{3} \mathrm{O}_{8+\delta}$ (R=Re, Pb). Розглянута трансформація параметрів вузької провідної зони в ділянці рівня Фермі. Показано існування кореляції між ефективною шириною зони та температурою надпровідного переходу $T_{\mathrm{c}}$.

Ключові слова: високотемпературна надпровідність, температура надпровідного переходу, коефіцієнт термоелектрорушійної сили, вузька провідна зона, пік густини станів, рівень Фермі. 